\title{
THYROID SURGERY: A COMPARISON OF COMMON COMPLICATIONS BETWEEN EXPERTS AND SURGEONS IN TRAINING
}

\author{
Syed Muhammad Asad Shabbir Bukhari, Zaheer-Ul-Hassan, Kamran Ashfaq Butt, Naeem Riaz*, Chaudhry Muhammad Bilal Akram**, \\ Amanat Ali Shah*** \\ Combined Military Hospital Peshawar/National University of Medical Sciences (NUMS) Pakistan, *Combined Military Hospital Gujranwala/ \\ National University of Medical Sciences (NUMS) Pakistan, **Pakistan Air Force Masroor, Karachi Pakistan, \\ ${ }^{* * *}$ Combined Military Hospital Hyderabad/National University of Medical Sciences (NUMS) Pakistan
}

\begin{abstract}
Objective: To determine the frequency of common complications of thyroid surgery by two types of surgeons.

Study Design: Comparative cross sectional.

Place and Duration of Study: Combined Military Hospital Rawalpindi \& Combined Military Hospital Peshawar, from Jan 2013 to Dec 2017.

Methodology: This study was conducted to assess the role of surgical skills in complications of thyroid surgery. Surgeons performing surgery for more than 5 years were considered expert and less than 5 years of experience were considered trainee for this specific surgery. Complications by both were analyzed by SPSS-21 and descriptive statistics were applied.

Results: A total of 482 surgeries were performed. Out of 407 were female and 75 were males. Mean age was $43.55 \pm 10.9$ years. Expert surgeons performed 300 cases and $16(5.3 \%)$ experienced some complication in 6 months of follow up.182 cases were performed by surgeons with lesser experience and $14(7.5 \%)$ cases developed complications over the period of follow up. Recurrent laryngeal nerve paralysis occurred in $2(0.67 \%)$ of experienced surgeons cases while 6 cases $(3.2 \%)$ of less experienced surgeons had the similar complication.

Conclusion: While the overall complication rates are not much different between experienced and lesser experienced surgeons, the rate of recurrent laryngeal nerve paralysis is significantly more, though still within the acceptable international complication rate for this particular surgery.
\end{abstract}

Keywords: Clinical competence, Recurrent laryngeal nerve injuries, Surgeons. Thyroidectomy.

How to Cite This Article: Bukhari SMAS, Hassan ZU, Butt KA, Riaz N, Akram CMB, Shah AA. Thyroid Surgery: A Comparison of Common Complications Between Experts and Surgeons in Training. Pak Armed Forces Med J 2021; 71(Suppl-3): S585-589.

Doi: https://doi.org/10.51253/pafmj.v1i1.7947

This is an Open Access article distributed under the terms of the Creative Commons Attribution License (https://creativecommons.org/licenses/by-nc/4.0/), which permits unrestricted use, distribution, and reproduction in any medium, provided the original work is properly cited.

\section{INTRODUCTION}

Over the past century Thyroid surgery has seen dramatic improvement in patients peri operative mortality and complications. It was one of the most challenging surgery 100 years back but gradual improvement in surgical practices viz a viz better sterile technique, better operative techniques, better skills and safer anesthesia has reduced mortality rates to less than $1 \%$ as compared to $40 \%$ at the turn of nineteenth century. Thyroid surgery has recently underwent a renaissance with the advent of endoscopic techniques for minimally invasive surgery followed by the introduction of robotic systems to assist in surgery. However introduction of advanced techniques have introduced their own plethora of complications. This include mental nerve injury following endoscopic transoral approach, anterior chest paresthesia and brachial plexus injury in robotic axillary approach and loss of sensation in facial area in endoscopic post auricular and axillary approach. Major complications of open surgery are

Correspondence: Dr Kamran Ashfaq Butt, Department of ENT Combined Military Hospital Peshawar-Pakistan massive hemorrhage, trauma to recurrent laryngeal nerves and permanent hypothyroidism. Improvement in training methodology as well as surgical practices has resulted significant improvement in common complication rates as well.

Of all the complications of thyroid surgery Injury to recurrent laryngeal nerve results in one of the most recognizable complications as patients voice is altered significantly. This results in causing much social embarrassment as well as significant psychosocial trauma. The incidence of RLN trauma after thyroid surgery fluctuates extensively in various countries, probably due to vast differences in surgeons training methodology and practice patterns, ranging from $0.4-7.2 \%$ for temporary paresis and from $0-5.2 \%$ for permanent paralysis.1-3 Permanent bilateral damage can cause respiratory distress needing emergency tracheotomy while mild unilateral paresis can manifest in the form of hoarseness of voice requiring observation only.

Good meticulous surgical techniques and mandatory habit to identify recurrent laryngeal nerves during thyroid surgery helps the surgeons to avoid the risk 
of damage. Similarly good meticulous closure and regular placement of drain ensures that hematoma formation is minimal. Expert surgeons are generally safer than less trained surgeons due to their experience to perform surgeries with early identification of nerves and the fact that they have achieved the level of naturalization regarding this surgery. What constitutes an expert surgeon however varies depending upon the training requirements and exposure of the surgeon during training period and after.

The objective of this study was to assess the frequency of common complications especially recurrent laryngeal nerve injury in expert and trainee surgeons during thyroid surgery in Combined Military Hospital $(\mathrm{CMH})$ Rawalpindi and $\mathrm{CMH}$ Peshawar. FCPS qualified surgeons performing surgery for more than 5 years were considered expert and those with less than 5 years of experience, were considered trainee for specific surgery. Hospital ethical committee's approval was obtained prior to commencement of the study.

\section{METHODOLOGY}

Permission was taken from the Institutional ethics review board $\mathrm{CMH}$ Peshawar application number 6 . This was a comparative cross sectional done in $\mathrm{CMH}$ Rawalpindi \& CMH Peshawar, from May 2013 to December 2017.

All patients, of both genders and any age with thyroid disease, after bringing to euthyroid status were included in the study. Patients with previous thyroid surgery, toxic disease and vocal cord paresis or paralysis were excluded. Patients were assigned to the surgeons by convenient sampling technique. All patients presenting in the OPD during the duration of study fulfilling the inclusion criteria were included in the sample size.

SPSS-21 was used for data analysis. Quantative data like age was analyzed as mean and standard deviation while the qualitative data like gender, indications, type of surgery, complications, recurrent laryngeal nerve palsy etc were measured as percentage and frequency. The difference of indications, complications esp. recurrent laryngeal nerve palsy and hematoma as well as hypocalcemia between the two study groups was tested. Incidence in both groups was compared using the chi square, Fischer exact test. $p$-value $<0.05$ was considered significant (Figures \& Tables).

\section{RESULTS}

Four hundred and eighty two thyroid surgeries were performed during the period of study, of these
$407(84.4 \%)$ were female and $75(15.6 \%)$ were males. Mean age was $43.55 \pm 10.9$ years. Expert surgeons performed 300 cases and 16 (5.3\%) experienced some complication in 6 months of follow up. One hundred and eighty two cases were performed by surgeons with lesser experience and 14 (7.6\%) cases developed complications over the period of follow up. Ninety three (31\%) total thyroidectomies, 107 (35.67) near total thyroidectomies and $100(33.33 \%)$ subtotal thyroidectomy /lobectomies were done by experienced surgeons during the period of study. Lesser experienced surgeons performed $39(21.4 \%)$ total $66(36.26 \%)$ near total thyroidectomies and $77(42.3 \%)$ subtotal thyroidectomy/lobectomies during the same period. Seventy eight $(26 \%)$ cases of malignancy and $222(74 \%)$ cases of be-

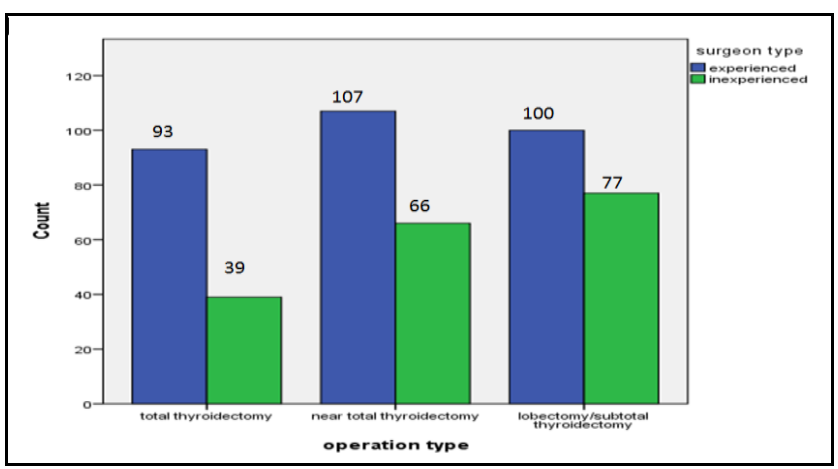

Figur-1: Operation type.

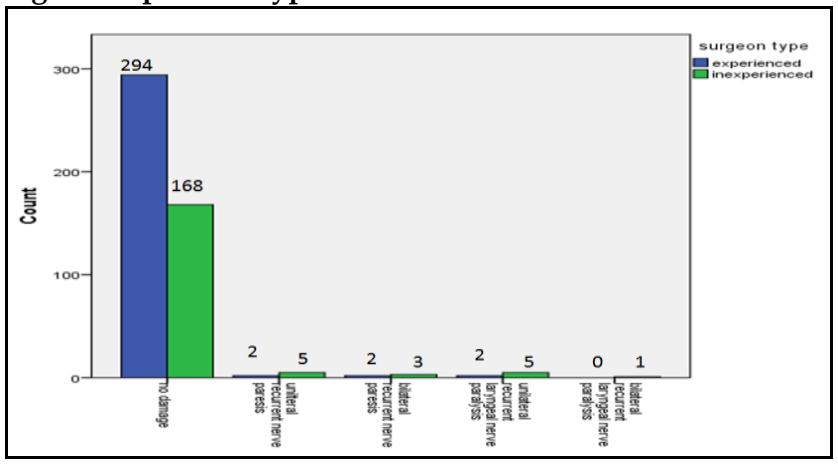

Figure-2: Recurrent laryngeal nerve injury, group wise comparison.



Figure-3: Hematoma status in both groups post surgery. 
nign causes of thyroid were operated upon by experienced surgeons while $24(13.2 \%)$ malignant and 158 $(86.8 \%)$ benign cases of thyroid surgery were done by less experienced surgeons. Recurrent laryngeal nerve paralysis occurred in 2 cases $(<1 \%)$ by experienced surgeons and 6 cases (3.2\%) by less experienced surgeons ( $p$-value $<0.05)$. Four cases $(1.3 \%)$ of experienced and 8 cases $(4.3 \%)$ by less experienced surgeons developed recurrent laryngeal paresis $(p$-value $<0.05)$. Three cases $(1 \%)$ of experienced surgeons developed hematoma requiring drainage while 1 case $(0.55 \%)$ of lesser experienced surgeon needed drainage of hematoma. Incidence of small hematomas was $9(3 \%)$ and 14 $(7.6 \%)$ in experienced and less experienced group respectively ( $p$-value $>0.05)$. 45 cases $(15 \%)$ and 15 cases $(8.2 \%)$ developed permanent hypocalcemia in experienced and lesser experienced group respectively. Transient hypocalcaemia affected $18(6 \%)$ and 7cases $(3.85 \%)$ in both groups respectively $(p$-value $<0.05)$. Parathyroid gland was routinely identified and preserved in near total and total thyroidectomies for benign diseases but was not identified in selected cases of malignancy. Parathyroid glands were not routinely identified in subtotal thyroid surgeries. Parathyroid hormone and Vitamin D levels pre and post surgical procedure were also recorded. Complete statistics are given in Table and Figure-1, 2 \& 3. thyroid surgery is still in earlier stages and advanced endoscopic and robotic techniques have not gained immense traction owing to the prohibitively high costs and limited medical facilities willing to spend such high amount of resources on an equipment for which there is limited patients and even more limited expertise. ${ }^{4}$ Most of the surgeons in Pakistan therefore prefer doing open thyroid surgery. Better surgical skills and proper identification of land marks help to ensure reduced incidence of complications. Complications of thyroid surgery especially permanent damage to recurrent laryngeal nerve can be particularly devastating for the patients especially females causing great psychological and physical impact on the quality of life. It can lead to hoarseness of voice, difficulty in breathing and sometimes aspiration. ${ }^{5}$ Some patients may take medico legal actions against the operating surgical specialist if the results are not to their satisfaction or appropriate medico legal documentation is not done prior to surgery. ${ }^{6,7}$ Proper identification of RLN by expert surgeons as done in our study, is a major reason of good results.

Our study revealed that while the incidence of complications is not significant between both groups however the incidence of serious complication such as recurrent laryngeal nerve paralysis is significantly less in experienced group. This, despite the fact that experi-

Table-I: Thyroid surgery findings.

\begin{tabular}{|c|c|c|c|c|c|c|}
\hline & \multicolumn{2}{|c|}{ Experienced Surgeon $(n=300)$} & \multicolumn{2}{|c|}{ Less Experienced Surgeon $(\mathrm{n}=182)$} & \multirow{2}{*}{$\begin{array}{c}p- \\
\text { value }\end{array}$} \\
\hline & & $\mathbf{n}$ & Pecentage & n & Pecentage & \\
\hline \multirow{2}{*}{ Gender } & Male & 47 & 15.7 & 28 & 15.4 & \multirow{2}{*}{0.92} \\
\hline & Female & 253 & 84.3 & 154 & 84.6 & \\
\hline \multirow{2}{*}{$\begin{array}{l}\text { Indication of } \\
\text { Surgery }\end{array}$} & Benign & 222 & 74 & 158 & 86.8 & \multirow{2}{*}{0.001} \\
\hline & Malignant & 78 & 26 & 24 & 13.2 & \\
\hline \multirow{3}{*}{$\begin{array}{l}\text { Type of } \\
\text { Surgery }\end{array}$} & Total Thyroidectomy & 93 & 31 & 39 & 21.4 & \multirow{3}{*}{0.043} \\
\hline & Near Total Thyroidectomy & 107 & 35.7 & 66 & 36.3 & \\
\hline & Subtotal Surgery/Lobectomy & 100 & 33.3 & 77 & 42.3 & \\
\hline \multirow{2}{*}{$\begin{array}{l}\text { Complications } \\
\text { Overall }\end{array}$} & Yes & 16 & 5.3 & 14 & 7.6 & \multirow{2}{*}{0.299} \\
\hline & No & 284 & 94.7 & 168 & 92.3 & \\
\hline \multirow{2}{*}{$\begin{array}{l}\text { Recurrent } \\
\text { Paralysis }\end{array}$} & Yes & 2 & 0.7 & 6 & 3.3 & \multirow{2}{*}{0.058} \\
\hline & No & 298 & 99.3 & 176 & 96.7 & \\
\hline \multirow{2}{*}{$\begin{array}{l}\text { Recurrent } \\
\text { Paresis }\end{array}$} & Yes & 4 & 1.3 & 8 & 4.4 & \multirow{2}{*}{0.065} \\
\hline & No & 296 & 98.7 & 174 & 95.6 & \\
\hline \multirow{3}{*}{ Hematoma } & No Hematoma & 288 & 96 & 167 & 9.2 & \multirow{3}{*}{0.057} \\
\hline & Small Hematoma & 9 & 3 & 14 & 7.7 & \\
\hline & Hematoma Requiring Drainage & 3 & 1 & 1 & 0.55 & \\
\hline \multirow{3}{*}{ Hypocalcemia } & No Hypocalcemia & 237 & 79 & 160 & 87.9 & \multirow{3}{*}{0.044} \\
\hline & Transient Hypocalcemia & 18 & 6 & 7 & 3.9 & \\
\hline & Permanent Hypocalcemia & 45 & 15 & 15 & 8.2 & \\
\hline
\end{tabular}

\section{DISCUSSION}

Thyroid surgery is a routinely performed neck surgery in tertiary care set ups. In Pakistan endoscopic enced surgeons in our study performed more total thyroidectomies overall as well in proportion to other surgeries compared to lesser experienced surgeons. 
Additionally tumor surgeries were more frequently undertaken by experienced surgeons. Similarly frequency of hematomas is also significantly less in experienced group but larger hematomas requiring drainage occurred more frequently in experienced group. Study done by Nathan et al observed an incidence rate of $0.3-3 \%$ for permanent recurrent laryngeal nerve injury 3-8\% for transient damage to recurrent laryngeal nerve which are similar to our incidence rates in both groups. ${ }^{8}$ Similar figure rates of $1-3 \%$ for recurrent laryngeal paralysis post thyroid surgery were also observed by Bhattacharya et al, in his article. ${ }^{5}$ The complication rates of these complications are therefore well within the norms of international literature even when less thyroid surgeons are performing operations.

Incidence of permanent hypocalcemia in our study was, $15 \%$ and $8.2 \%$ in experienced and less experienced group respectively was higher than observed by Randall. Baldassarre et al, who observed a $9 \%$ incidence of permanent hypocalcemia in patients undergoing total thyroidectomy. ${ }^{9}$ One reason for this maybe the more aggressive approach adopted by our surgical team in management of thyroid tumors willing to risk permanent hypocalcemia rather than risk leaving malignant tissue behind, this is supplemented by the Randall et al, who in the same article observed a $23 \%$ incidence of permanent hypocalcemia in patients undergoing thyroidectomy for malignant disease. ${ }^{9}$ Incidence of transient hypocalcemia was similar in our study, 6 and $3.9 \%$ in experienced vs. less experienced group to an article by Pattou, F who noted an incidence of $5.4 \%$ for transient hypocalcemia post operatively. ${ }^{10}$ Another study by Eleni. Efremidou et al, observed complication rates of $7 \%$ for transient hypocalcemia. However more effort needs to be put into identification of parathyroid gland during surgery to avoid permanent hypocalcemia post operatively. Another observation made in our study was the relatively frequent complication of post operative hematoma requiring drainage in experienced surgeon group $(1 \%)$ which was higher than the observed incidence $(0.2 \%)$ by Eleni. Efremidou. ${ }^{11} \mathrm{~A}$ reason maybe that experienced surgeons were performing more difficult cases hence the increased incidence. However further research may be needed to prove this point.

The comparable complication rates also speak volumes of the robustness of training imparted and proficiency of young surgeons in our set up. The overall incidence of complications and the incidence of laryngeal nerve damage in both groups are compar- able to internationally acceptable complication rates for thyroid surgery. Regular identification of recurrent laryngeal nerve helps to identify abnormal anatomical cases. Trainee surgeons could improve their surgical skills under supervision of expert surgeon. Intraoperative nerve stimulation of recurrent laryngeal nerve is another method to avoid nerve injury.12,13 A good number of surgeons prefer Intra Operative Nerve Monitoring (IONM) in all cases of thyroid surgery. However, many surgeons particularly in Pakistan prefer direct visualization of nerve for safe surgery. In our setup intraoperative nerve monitoring is available and is used depending upon the surgeon's preference but for the duration of the study it was not used. IONM causes less incidence of temporary nerve palsy in some studies. ${ }^{14,15}$ In a metanalysis comparing the incidences of nerve injury in thyroid surgery with and without intra operative nerve monitoring, the main benefit of IONM is to guide the surgeon in anatomical variations of nerve course, ${ }^{16}$ non recurrence of right nerve, ${ }^{17,18}$ and nerve displacement by thyroid nodule. ${ }^{19-}$ ${ }^{21}$ It also helps in video assisted thyroidectomy. ${ }^{22}$ It is also very helpful in revision thyroid surgery, ${ }^{23}$ where nerve may have been displaced from its regular location and scar tissue hampers bloodless dissection.

A future direction that this study might be improved upon is studying the incidence of nerve damage in revision cases between similar groups of surgeons with and without using intraoperative nerve monitoring. Another aspect could be grading the difficulty of surgery based on international standards and then comparing the complication rates removing patient bias during the process and giving a better idea of the exact incidence.

\section{CONCLUSION}

Experienced surgeons tend to make lesser mistakes during thyroid surgeries in our setups but lesser experienced surgeons still have complication rates within the norms of international acceptable limits. Proper identification of recurrent laryngeal nerve, meticulous planning and dissection in appropriate plane are the best ways of avoiding complications during surgery.

\section{Conflict of Interest: None.}

\section{Authors' Contribution}

KAAB: Substantial, SMASB: Intellectual, ZUH: Direct, NR: Intellectual, CMBA: Intellectual, AAS: Proof reading.

\section{REFERENCES}

1. Pantvaidya G, Mishra A, Deshmukh A, Pai PS, D'Cruz A. Does the recurrent laryngeal nerve recover function after initial dysfunction in patients undergoing thyroidectomy?. Laryng Invest Otolaryngol 2018; 3(3): 249-252. 


\section{Thyroid Surgery}

2. Hu J, Zhao N, Kong R, Wang D, Sun B, Wu L. Total thyroidectomy as primary surgical management for thyroid disease: surgical therapy experience from 5559 thyroidectomies in a less-developed region. World J Surg Oncol 2016; 14(1): 20-25.

3. Bai B, Chen W. Protective effects of intraoperative nerve monitoring (IONM) for recurrent laryngeal nerve injury in thyroidectomy: meta-analysis. Sci Rep 2018; 8(1): 7761-7765.

4. Sephton BM. Extracervical Approaches to thyroid surgery: evolution and review. Minim Invasive Surg 2019; 2019(1): 1-14.

5. Bhattacharyya N, Fried MP. Assessment of the morbidity and complications of total thyroidectomy. Arch Otolaryngol Head Neck Surg 2002; 128(2): 389-392.

6. Raffafelli M, Lombardi C, Bellantone R, Crea CD. Lesnik, andre potenza and gregory randolph, avoiding complications in thyroid and parathyroid surgery, stell and maran's textbook of Head and Neck Surgery and Oncology Fifth edition, 2013, https://publires.unicatt.it/it/publications/avoidingcomplications-in-thyroid-and-parathyroid-surgery-9

7. Kern KA. Medicolegal analysis of errors in diagnosis and treatment of surgical endocrine disease. Surg 1993; 114(2): 1167-1173.

8. Hayward NJ, Grodski S, Yeung M, Johnson WR, Serpell J. Recurrent laryngeal nerve injury in thyroid surgery: a review. ANZ J Surg 2013; 83(1-2): 15-21.

9. Baldassarre RL, Chang DC, Brumund KT, Bouvet M. Predictors of hypocalcemia after thyroidectomy: results from the nationwide inpatient sample. ISRN Surg 2012; 2012(1): 838614.

10. Pattou F, Combemale F, Fabre S, Carnaille B, Decoulx M, Wemeau JL, et al. Hypocalcemia following thyroid surgery: incidence and prediction of outcome. World J Surg 1998; 22(7): 718724 .

11. Efremidou EI, Papageorgiou MS, Liratzopoulos N, Manolas KJ. The efficacy and safety of total thyroidectomy in the management of benign thyroid disease: a review of 932 cases. Can J Surg 2009; 52(1): 39-44.

12. Shedd DP, Burget GC. Identification of the recurrent laryngeal nerve: electrical method for evaluation in the human. Arch Surg 1966; 92(2): 861-864.

13. Christoforides C, Papandrikos I, Polyzois G, Roukounakis N, Dionigi G, Vamvakidis K. Two-stage thyroidectomy in the era of intraoperative neuromonitoring. Gland Surg 2017; 6(5): 453-463.
14. Wojtczak B, Sutkowski K, Kaliszewski K, Głód M, Barczyński M. Experience with intraoperative neuromonitoring of the recurrent laryngeal nerve improves surgicalskills and outcomes of nonmonitored thyroidectomy. Langenbecks Arch Surg 2017; 402(4): 709-717.

15. Chen JY, Shen Q. A New Technique for Identifying the Recurrent Laryngeal Nerve: Our Experience in 71 Patients. Chin Med J (Engl) 2018; 131(7): 871-872.

16. Rulli F, Ambrogi V, Dionigi G, Amirhassankhani S, Mineo TC, Ottaviani F. Meta-analysis of recurrent laryngeal nerve injury in thyroid surgery with or without intraoperative nerve monitoring acta otorhinolaryngologica italica. Acta Otorhinolaryngol Ital 2014; 34(2): 223-229.

17. Le QV, Ngo DQ, Ngo QX. Non-recurrent laryngeal nerve in thyroid surgery: a report of case series in vietnam and literature review. Int J Surg Case Rep 2018; 50(2): 56-59.

18. Demiryas S, Donmez T, Cekic E. Effect of nerve monitoring on complications of thyroid surgery. North Clin Istanb 2018; 5(1): 14-19.

19. Randolph GW. Surgical anatomy of the recurrent laryngeal nerve. In: Randolph GW editor, $1^{\text {st }}$ edition. Surgery of the Thyroid and Parathyroid Glands. Philadelphia, PA: Saund 2003, Available at: http://osp.mans.edu.eg/tmahdy/surgeons/ ebooks/Books/Surgery\%20of\%20the \%20Thyroid \%20and $\% 20$ Parathyroid\%20Glands,\%20Oertli.pdf

20. Dzodic R, Markovic I, Santrac N, Buta M, Djurisic I, Lukic S. Recurrent laryngeal nerve liberations and reconstructions: a single institution experience. World J Surg 2016; 40(2): 644-651.

21. Uludağ M, Yetkin G, Oran EŞ, Aygün N, Celayir F, İşgör A. Extralaryngeal division of the recurrent laryngeal nerve: A common and asymmetric anatomical variant. Turk J Surg 2017; 33(3): 164168.

22. Del Rio P, Viani L, Montana CM, Cozzani F, Sianesi M. Minimally invasive thyroidectomy: a ten years experience. Gland Surg 2016; 5(3): 295-299.

23. Barczynski M, Konturek A, Pragacz K, Papier A, Stopa M, Nowak W. Intraoperative nerve monitoring can reduce prevalence of recurrent laryngeal nerve injury in thyroid reoperations: results of a retrospective cohort study. World J Surg 2014; 38(1): 599-606. 